\title{
Posterior Parietal Artery
}

National Cancer Institute

\section{Source}

National Cancer Institute. Posterior Parietal Artery. NCI Thesaurus. Code C33372.

An intracranial artery that supplies the posterior part of the parietal lobe. 